\title{
IMPLEMENTATION OF CROSS-CURRICULAR INTEGRATION IN THE PROFESSIONAL TRAINING OF FUTURE TEACHERS OF PHYSICAL CULTURE
}

\section{Vitaliy Demchenko ${ }^{1}$}

Ph.D. (Pedagogy), Lecturer of the Department of Humanities and natural and economic disciplines of the Central Ukrainian Institute, Interregional Academy of Personnel Management, Kropyvnytskyi, Ukraine, email:v.demchenkoffu@gmail.com, ORCID: https://orcid.org/0000-0002-7181-5237

Abstract. The article examines the effectiveness of interdisciplinary integration in the training of future physical education teachers. The purpose of the article is to test the effectiveness of interdisciplinary integration in the training of future teachers of physical education. Research methodology includes: empirical methods: observations, questionnaires, pedagogical experiment is for checking the effectiveness of interdisciplinary integration in the training of future teachers of physical education; methods of mathematical statistics are for processing the results of experimental work. Analysis of the effectiveness of the implementation of interdisciplinary integration in the training of future teachers of physical education is based on a certain system of standards: pedagogical orientation, independence and professional maturity, which we used to diagnose their development by those activities that included students of the experimental group.

After analyzing the data, it was found that students of the control and experimental groups have significant differences on such scales as: awareness, decision-making, planning and communication; as well as a positive trend on the scales: mnemonic, volitional and mental. According to the study, it can be said that future physical education teachers of the experimental group are more knowledgeable and confident in choosing their profession, they more rationally and adequately assess the situation and plan their future more thoughtfully than students in the control group.

Keywords: integration, interdisciplinary integration, professional training, future teachers of physical education.

JEL Classification: JEL I0; I20

Formulas: 0; fig.: 1; tabl.: 3; bibl.: 7

Introduction. The principle of integration is one of the most important principles of development of modern educational systems. This principle is innovative, calls for a radical restructuring of the learning process, based on the synthesis of educational areas, which involves obtaining a holistic educational product that ensures the formation of integral personality traits of the learners, his harmonious entry into society, development of professional competencies.

Literature review. Considering ways to implement an integrated approach in the educational process of higher education, scientists suggest different ways to solve this problem. First of all, it applies to semantic integration: the creation of integrated courses, integration of subjects, their components - knowledge, skills (L. I. Balashov [1], M. M. Berulava [2], O. O. Galitskyh [3]). There is a large amount of literature on the problems of "practical synthesis" - the combination and using of various techniques, methods, ways of education and training (V. I. Zagvyazinsky [4], V. D. Semyonov [7], etc. However, today the university faces a fundamentally new task - to create an integrated model of education of future teachers in higher education in order to program a specialist who has the skills and professional mobility, responds quickly to changes in practice and research, is able to demand and 
use the device of each a separate discipline in integration with others as a way of solving tasks (problems) in cognitive and professional activities.

The concept of integration in pedagogy is polysemantic and, according to the research of E. N. Puzankova and N. V. Bochkova, can mean "a way to identify, introduce and construct hierarchical relationships between elements of pedagogical systems; a way of building pedagogical models; way , leading the system to integrity, the way to reveal patterns in pedagogical phenomena, processes and systems, the path to a holistic, comprehensive study of pedagogical phenomena and processes "[6, p. 12].

The integration process involves planning special classes on topics that are common to several subjects that can be taught by different teachers. In the process of training future teachers of physical culture in a pedagogical institution of higher education opens wide opportunities for horizontal integration. On the basis of interdisciplinary connections, integrated classes are built, which are characterized by significant and diverse opportunities. Here is the unification of knowledge, the ability to transfer knowledge from one field to another. It acts as a stimulator of cognitive activity of students, develops the need for a systematic approach to the object of knowledge. Combining scientific knowledge from different disciplines, integration frees up learning time, that can be used for the full implementation of differentiation in education [5, p. 21].

Aims. The purpose of the article is to test the effectiveness of interdisciplinary integration in the training of future teachers of physical education.

Methods. Empirical: observations, questionnaires, pedagogical experiment is for checking the effectiveness of interdisciplinary integration in the training of future teachers of physical education; methods of mathematical statistics are for processing the results of experimental work.

Results. The analysis of the effectiveness of the implementation of interdisciplinary integration in the training of future teachers of physical education is based on our defined system of criteria: pedagogical orientation, independence and professional maturity, which we used to diagnose their development in those activities that included students of the experimental group.

Involvement of students in the independent is modeling of integrative connections, first of all, was carried out by the possibilities of the game method. The level of students' independence has changed the most significantly. The assessment of the development of the criterion of "independence" was based on the method of A. A. Rean and V. O. Yakunin and the test of G. S. Prigin. Using the method of diagnosing learning motivation, we identified the main groups of motives and determined their average level (table 1).

The analysis of this table allows us to conclude that in the motivational structure of students of the expert group the leading place is occupied by motives related to professional self-realization. These motives for students are those that actually work and motivate action, because they are related to close professional goals. But the awareness of these goals needs to be supported by procedural motivation, which is accompanied by the emotional attitude of students to the training process. 
Table 1

The diagnosis of learning motivation

\begin{tabular}{|l|c|c|c|c|}
\hline \multirow{2}{*}{ Groups of motives } & \multicolumn{2}{|c|}{ Control group } & \multicolumn{2}{c|}{ Experimental group } \\
\cline { 2 - 5 } & $\begin{array}{c}\text { Medium } \\
\text { point }\end{array}$ & Grade & Medium point & Grade \\
\hline Communicative motives & 3,32 & 4 & 3,69 & 3 \\
\hline Motives of avoidance & 4,55 & 1 & 0,57 & 7 \\
\hline Motives of prestige & 2,84 & 6 & 3,15 & 6 \\
\hline Professional motives & 2,83 & 7 & 5,99 & 1 \\
\hline $\begin{array}{l}\text { Motives of creative self- } \\
\text { realization }\end{array}$ & 3,17 & 5 & 5,68 & 2 \\
\hline $\begin{array}{l}\text { Educational-cognitive } \\
\text { motives }\end{array}$ & 3,45 & 3 & 3,57 & 5 \\
\hline Social motives & 3,49 & 2 & 3,6 & 4 \\
\hline
\end{tabular}

In order to diagnose the style of educational activities of future teachers of physical culture and assign them to the group of "autonomous" or "dependent", we used a special test questionnaire G. S. Prigin. We consider this diagnostic technique to be well-founded, it has high validity (content validity and validity of criteria) and reliability. The method diagnoses both main types of students: "autonomous" and "dependent", and also allocates the third group - "indeterminate" students.

For each match of the answer the subject is given 1 point. Students who scored 11 points or more, we referred to the group of "autonomous". Students who scored 7 points or lower, we classified as "addicted". With regard to students who scored 8, 9, 10 points, a definite conclusion cannot be drawn. The results of research on the phenomenon of "autonomy / dependence" in educational activities are shown in table 2.

Table 2

Autonomy / dependence in educational activities

\begin{tabular}{|c|c|c|c|}
\hline \multirow{2}{*}{ Sample } & \multicolumn{3}{|c|}{ Number of students, \% } \\
\cline { 2 - 4 } & "autonomy" & "dependence" & "indeterminate" \\
\hline Control group & 5,5 & 65 & 29,5 \\
\hline Experimental group & 50 & 24 & 26 \\
\hline
\end{tabular}

The fact that $26 \%$ belong to the "indeterminate" cannot be called positive. It is noteworthy that a high percentage of students who belong to the type of "autonomous" - 50\%.

The study of the influence of independent modeling of integrative relations was also conducted with the help of the questionnaire "Professional readiness" by A. P. Chernyavskaya. According to the data obtained, in the experimental group, the readiness on all scales studied as a whole increased. The average value of the autonomy index increased from $13.13 \pm 3.27$ to $15.27 \pm 2.60$; the average value of awareness increased from $13.47 \pm 2.61$ to $15.53 \pm 1.96$; the average value of the decision-making indicator increased from $13.40 \pm 1.99$ to $15.73 \pm 1.44$; the average value of planning increased from $14.00 \pm 1.07$ to $15.33 \pm 0.99$; the average value of 
the emotional attitude to the professional self-determination - from $14.07 \pm 1.87$ to $16.27 \pm 1.58$; the average value of the general professional readiness of the subjects increased from $68.07 \pm 6.08$ to $78.33 \pm 5.66$. We assessed the statistical significance of the identified differences using the T-standart of Wilcoxon. In the control group, readiness indicators on all studied scales of professional readiness have not changed.

The whole system of traditional pedagogy is focused on subject-object interaction (student - only the object of action), on strict and direct management, on directive methods of teaching and education, which ultimately leads to the formation of the dependent type of students. The formation of a particular style of educational activity has a multifactorial conditionality: it depends on the characteristics of the student's personality, abilities and so on. But we consider the pedagogical factor to be extremely important.

Investigating the impact of self-modeling of integrative relationships, which was carried out by the possibilities of the game method, we found that its use contributes to: the growth of cognitive activity, the development of responsibility in cognitive activity. In the experimental group there is a steady tendency to plan cognitive actions. Creating a situation of success with the help of the game method influenced the growth of a positive emotional background. One of the important indicators of this is the spread of active expression of cognitive interest of students in their free time.

According to the results of diagnostic measurements of the greatest development due to the influences of the special course "Psychological and pedagogical practice" developed and implemented by us, which aims to develop understanding of high social significance of pedagogical profession and increase psychological and pedagogical readiness for professional activity, the criterion "pedagogical orientation" showed. It should be noted that during the implementation of this course, the experimental group was widely introduced into the educational process vertical and horizontal integration based on inter- and intra-subject connections.

The results of our work on the degree of influence of each of the above positions on the pedagogical orientation of the future physical education teacher allowed us to draw the following conclusions: special course - more affects the motivational and value sphere of personality by meeting the needs of self-affirmation, self-expression, forms initial experience of professional and social activity ; integration classes dominate over all others in terms of the level of influence on the development of motivational and value spheres, on pedagogical attitudes to pedagogical activity, on the development of consciousness and self- consciousness, formation of pedagogical experience, internalization of which leads to higher level of social activity and responsibility. .

Now let's turn to the results obtained by the method of "Morphological test of life values". Values on the scales of this questionnaire are given in table 3 . This technique is called "Morphological test of life values" based on the goals and objectives of the study - to determine the motivational and value structure of personality. The main diagnostic construct of this technique are terminal values. By 
the term "value" we mean the attitude of the subject to the phenomenon, fact of life, object and subject, and its recognition as one that is of vital importance.

The list of life values includes:

- self-development, that is knowledge of their own individual characteristics, constant development of their abilities and other personal characteristics;

- spiritual satisfaction, that is guidance of moral principles, the predominance of spiritual needs over material ones;

- creativity, that is the realization of their creative potential, the desire to change the surrounding reality;

- active social contacts, that is the establishment of favorable relations in various spheres of social interaction, the expansion of their interpersonal ties, the realization of their social role;

- own prestige, that is gaining their recognition in society by imitating certain social requirements;

- high financial status, that is recourse to the factors of material well-being as the main meaning of existence;

- achievement, that is setting and solving certain life tasks as the main life factors;

- preservation of one's own individuality, that is the predominance of one's own thoughts, views, beliefs over the generally accepted ones, protection of one's uniqueness and independence.

Table 3

Significance of manifestations of thermal values according to the method: "Morphological test of life values"

\begin{tabular}{|l|c|c|}
\hline \multicolumn{1}{|c|}{ Scale } & $\begin{array}{c}\text { Expert group } \\
\text { (average value) }\end{array}$ & $\begin{array}{c}\text { Control group } \\
\text { (average value) }\end{array}$ \\
\hline Self-development & 53,1 & 37 \\
\hline Spiritual satisfaction & 33,7 & 44,9 \\
\hline Creativity & 41 & 39 \\
\hline Active social connections & 52,1 & 32,5 \\
\hline Own prestige & 33,5 & 52,7 \\
\hline High financial position & 36 & 54,4 \\
\hline Achievement & 50 & 49 \\
\hline $\begin{array}{l}\text { Preservation of own } \\
\text { individuality }\end{array}$ & 38,1 & 28 \\
\hline
\end{tabular}

From the table we see that the highest value is observed on the scale of selfdevelopment. High scores on this scale mean that people strive to learn about their individual characteristics, to the constant development of their abilities and other personal characteristics. It also demonstrates a responsible attitude to one's responsibilities and a display of competence in matters.

The next important factor for our subjects is active social contacts, that is the establishment of favorable relations in various spheres of social interaction, the expansion of their interpersonal relationships, the realization of their social role. For such people, as a rule, all aspects of human relationships are important, they are often convinced that the most valuable thing in life is the opportunity to communicate and interact with other people. 
From the group of pragmatic values, high importance was acquired only on the scale of achievement, that is the formulation and solution of certain life tasks as the main life factors. Such people, as a rule, carefully plan their lives, setting specific goals at each stage and believe that the main thing is to achieve these goals.

One of the powerful means of developing the studied readiness, as we have already noted, is to involve students in project activities.

As a result of the study of professional maturity, significant differences in the studied indicators were revealed in students according to the method of "Professional readiness" of A. P. Chernyavska (Fig. 1).

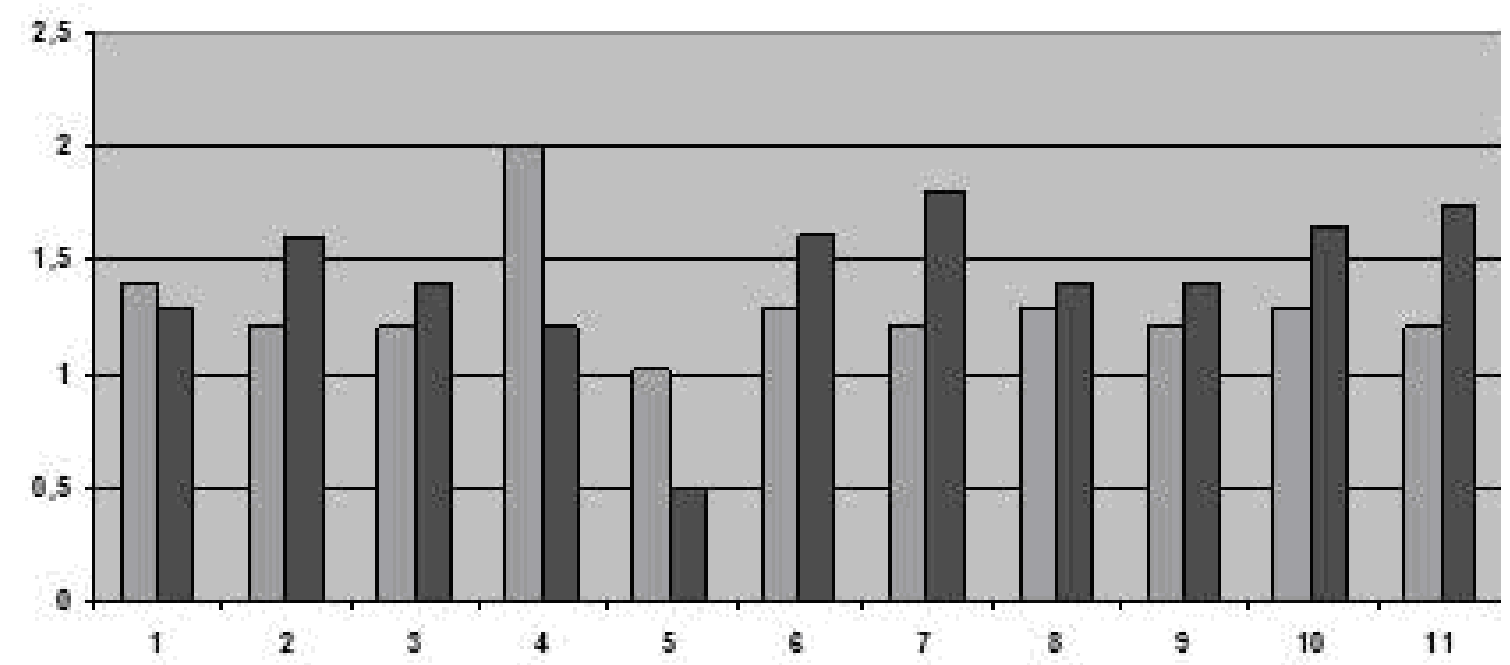

Fig. 1. The level of development of the components of "professional readiness"

According to the study of the manifestation of the corresponding components, we can see that the students of the experimental group are characterized by a high level autonomy, that is independence in choosing the field of professional activity, while awareness and willingness to make decisions are expressed at a high level. Career planning and the emotional attitude to choosing a profession are also presented at a high level.

Discussion. After processing the mathematical dictates, obtained from the results of the study of the control and experimental groups, using the nonparametric test Mann-Whitney for independent samples, the following results were obtained.

Significant differences were found on the following scales:

- awareness ( $\mathrm{U}=153,5000, \mathrm{p}=0,002037)$ : the ability to have a positive attitude to all types of work, the ability to distinguish between professions, as well as to identify the basic requirements of the profession to man;

- decision-making $(\mathrm{U}=211.5000, \mathrm{p}=0.050041)$ : the ability to make informed, rational decisions (this is a special type of human activity aimed at choosing a way to achieve the goal, the process of choosing one or more options for action from many others);

- planning $(\mathrm{U}=138.5000, \mathrm{p}=0.000736)$ : this is a process that is a coordinated activity to choose ways to achieve the goal, based on the adopted strategy or 
technology of the activity; the order and sequence of its execution is planned in advance; implementation of any program;

- communicative $(\mathrm{U}=195.5000, \mathrm{p}=0.023206)$ : this is the process of interaction between people, during which interpersonal relationships arise, manifest and are formed. Communicativeness involves the exchange of thoughts, feelings, experiences, and therefore these skills are very important in society. Some professions have obliged to pay more attention to them, because in certain activities the main method of work is communication.

We also follow the trend on the following scales:

- mnemonic ( $U=220,0000, p=0,072701)$ : there are actions that are implemented in the learning process, include the following operations: orientation in the semantic structure material, dismemberment and grouping of semantic elements, establishing links between structural units of the text, recoding verbal information into figurative, consolidation of memorized material, as a whole and in parts;

- mental $(\mathrm{U}=216.5000, \mathrm{p}=0.062517)$ : this is a process that provides answers to such questions that cannot be solved by direct, sensory reflection. Thanks to thinking, a person correctly navigates in the world around him, using previously obtained generalizations in a new, specific situation.

After analyzing the obtained data, it was found that the students of the experimental group are more dominated by the ability to make more informed and considered decisions, they plan their future professional life more rationally. Students in the experimental group are more communicative than students in the control group.

Results. In conclusion, the students of the control and experimental groups were found to have significant differences on such scales as: awareness, decision-making, planning and communication; as well as a positive trend on the scales: mnemonic, volitional and mental. According to the study, it can be said that future teachers of physical education of the experimental group are more knowledgeable and confident in choosing their profession, they more rationally and adequately assess the situation and plan their future more thoughtfully than students in the control group.

\section{References:}

1. Balashova, L. I. (1973), Odnovremennoye izucheniye vzaimosvyazannykh tem na uroke [Simultaneous study of interrelated topics in the classroom], M.: MOPI, 144 s. [in Russian].

2. Berulava, M. N. (1993), Integratsiya soderzhaniya obrazovaniya [Integration of the content of education], M.: Biysk: Nauchno-izdatel'skiy tsentr BiGPI, 172 s. [in Russian].

3. Galitskikh, Ye. O. (2001), Integrativnyy podkhod kak teoreticheskaya osnova professional'nolichnostnogo stanovleniya budushchego pedagoga $v$ universitete [The integrative approach as a theoretical basis for the professional and personal development of a future teacher at the University], SPb.: Izd-vo RGPU im. A. I. Gertsena, 264 s. [in Russian].

4. Zagvyazinskiy, V. I. (2001), Teoriya obucheniya: sovremennaya interpretatsiya [Teaching theory: modern interpretation], M.: AcademiA, 188 s. [in Russian].

5. Mokrousova, T. V. (2011), Vozmozhnosti integrirovannykh urokov [Possibilities of integrated lessons], Fizicheskaya kul'tura v shkole. M.: Shkola-press, № 7. S. 21-24. [in Russian].

6. Puzankova, Ye. N. (2009), Sovremennaya pedagogicheskaya integratsiya, yeye kharakteristiki [Modern pedagogical integration, its characteristics], Obrazovaniye i obshchestvo, 2009, № 1, S. 9-13. [in Russian].

7. Semenov, V. D. (1993), Pedagogika sredy [Pedagogy of the environment], Yekaterinburg: Izd-vo Ural. ped. in-ta, 63s. [in Russian]. 